\title{
Erratum: Fragility of network-forming glasses: A universal dependence on the topological connectivity [Phys. Rev. E 92, 062804 (2015)]
}

\author{
D. L. Sidebottom
}

(Q) (Received 29 July 2019; published 13 August 2019)

DOI: 10.1103/PhysRevE.100.029901

At the time of publication, we were unaware of earlier work by Nemilov [1,2], whose early suggestion that fragility might be correlated with average bond connectivity is relevant to the topic of our paper. These citations should be included:

[1] S. V. Nemilov, in Viscosity and Structure of Glass, edited by E. A. Porai-Koshitz, The Structure of Glass, Proceedings of the Fourth All-Union Conference on the Glassy State Vol. 6 (Consultants Bureau, New York, 1966), Pt. 1, p. 58.

[2] S. V. Nemilov, Review: Structural aspect of possible interrelation between fragility (length) of glass forming melts and Poisson's ratio of glasses, J. Non-Cryst. Solids 353, 4613 (2007). 